\title{
Penyuluhan "Practical Approach of Service Excellent" Untuk Dosen Dan Karyawan Di Fakultas Hukum Universitas Tarumanegara
}

\author{
Leonnard Ong ${ }^{1}$ \\ ${ }^{1}$ Sekolah Tinggi Manajemen Ipmi, Jakarta, Indonesia 12750 \\ Author E-mail: leonnard.ong@ipmi.ac.id
}

\section{A B S T R A K}

Globalisasi, liberalisasi pendidikan tinggi dan tingginya iklim persaingan menyebabkan perguruan tinggi saat ini seharusnya tidak hanya berfokus pada masalah administrasi dan indikator-indikator kuantitatif, tetapi yang paling penting adalah memberikan kualitas pelayanan yang tinggi bagi konsumen utama mereka. Dalam hal ini, terdapat dua jenis konsumen perguruan tinggi, yaitu konsumen internal dan konsumen eksternal. Model service-value chain menjelaskan hubungan antar kedua konsumen tersebut dan dua jenis service quality, yaitu internal dan external service quality. Kemampuan perguruan tinggi menjamin internal service quality akan membawa kepada external service quality yang akan menghasilkan kepuasan dan loyalitas mahasiswa. Kedua hal ini akan menjamin perguruan tinggi, khususnya perguruan tinggi swasta agar dapat bersaing dan memiliki keunggulan kompetitif dalam jangka panjang. Penyuluhan ini bertujuan untuk memberikan pengetahuan dan wawasan serta memberikan motivasi kepada para 22 dosen dan 19 karyawan di Fakultas Hukum, Universitas Tarumanegara mengenai konsep service quality berdasarkan model service-value chain, langkahlangkah aplikasinya, tingkatan service quality dan customer touch points. Metode penyampaian dilakukan dengan ceramah, tanya jawab, dan diskusi dengan peserta. Selama kegiatan ini berlangsung, peserta dapat mengikuti penyuluhan dengan interaktif dan sangat baik. Diharapkan adanya penyuluhan lanjutan mengenai materi yang disampaikan untuk memberikan pengetahuan lanjutan dan mengevaluasi praktik-praktik yang telah dilakukan pasca penyuluhan.

Kata Kunci: Kualitas pelayanan pendidikan tinggi, Model service-value chain, internal dan external service quality, Konsep service quality.

\section{A B S T R A C T}

Globalization, liberalization of universities and high competitiveness should currently make the universities not only focus on the administrative stuff and the quantitative indicators, but most importantly to provide the highest service quality to their main customers. There are two types of universities' customers, i.e. internal and external customers. The model of service-value chain explains the relationship between those two customers and two types of service qualities, i.e. internal and external service quality. The capability of the university to maintain the internal service quality will bring the external service quality to achieve students' satisfaction and loyalty. These two achievements will guarantee the university, particularly the private university, to compete and to have the excellence competitiveness in the long term. This workshop aimed to provide the knowledge and insight as well the motivation to all 22 lecturers plus 19 employees of the Law Faculty of Tarumanegara University, 
regarding to service quality concept based on service-value chain model, the application steps, service quality levels and customer touch points. The methodology was chosen by giving discourse, question and answer and discussion among the participants. During the activities, the participants were able to interactively involve very well. It is expected further workshop for the similar subject can be provided to extend the knowledge and to evaluate the practices which will have been made after the workshop.

Keywords: Entrepreneur, Orphanage, Makrameart, Onlinemarketing.

Copyright (C) 2019 Authors. This is an open access article distributed under the Creative Commons Attribution License, which permits unrestricted use, distribution, and reproduction in any medium, provided the original work is properly cited.

\section{PENDAHULUAN}

Globalisasi dan liberalisasi pendidikan tinggi dewasa ini menyebabkan negara-negara berkembang termasuk Indonesia harus menghadapi pasar bebas pendidikan yang merupakan respons atas peningkatan permintaan berkualitas tinggi dan perkembangan teknologi informasi. Persaingan antar penyedia jasa pendidikan bukan hanya terjadi antara perguruan tinggi negeri dan swasta, namun juga terhadap perguruan tinggi di negara-negara maju secara langsung maupun melalui metode pembelajaran e-learning. Meskipun angka partisipasi kasar pendidikan tinggi Indonesia masih jauh tertinggal dibandingkan dengan negara-negara ASEAN seperti Malaysia, Filipina dan Singapura, namun pertumbuhan angka partisipasi tersebut menunjukkan tren kenaikan yang positif selama 10 tahun terakhir.

Permintaan akan pendidikan yang berkualitas tinggi yang mampu memenuhi peluang dan tantangan pasar semakin meningkat. Kondisi ini menjadi peluang sekaligus tantangan bagi perguruan tinggi dalam mempertahankan dan meningkatkan loyalitas konsumen mereka. Banyaknya jumlah perguruan tinggi swasta dan kualitas jasa dan keunikan yang beragam dari masing-masing perguruan tinggi menyebabkan derajat kompetisi antar perguruan tinggi swasta sangat tinggi. Jumlah perguruan tinggi yang ada saat ini melebihi kapasitas pasar dalam menyediakan mahasiswa setiap tahunnya.

Akibatnya, tidak sedikit program studi dan fakultas yang memiliki rasio mahasiswa yang tidak seimbang. Selain itu, kemudahan akses informasi melalui teknologi digital membawa kemudahan bagi masyarakat untuk mendapatkan informasi baik positif maupun negatif mengenai perguruan tinggi. Hal ini jika tidak dapat dimanfaatkan secara cerdas dan efektif oleh perguruan tinggi, akan menjadi ancaman bagi institusi dan ketidakmampuan memberikan jasa pendidikan tinggi yang berkualitas dan berdaya saing dalam jangka panjang (sustainable competitive advantage).

Untuk mencapai sustainable competitive advantage tersebut, service excellence telah menjadi indikator utama perguruan tinggi selama bertahun-tahun (Khan \& Matlay, 2009). Mahasiswa dan para stakeholder terkait bukan lagi menganggap pendidikan sebatas kebutuhan untuk memasuki dunia kerja, namun juga sebagai investasi yang mengharapkan tingkat pengembalian tinggi.

Kemampuan perguruan tinggi dalam memenuhi keinginan konsumen mereka melebihi ekspektasi akan membawa kepada kepuasan, image positif, word of mouth dan loyalitas (Leonnard, Daryanto, Sukandar \& Yusuf, 2015; Leonnard \& Susanti, 2018). Service excellence tersebut merupakan bagian integral dari jasa pendidikan tinggi yang melibatkan berbagai pihak termasuk para dosen dan karyawan serta para stakeholder lain yang bertanggung jawab langsung dalam penyediaan jasa berkualitas terhadap mahasiswa mereka (Matlay, 2009). Sehingga dalam upaya memberikan harapan tersebut, diperlukan sebuah penyuluhan tentang "practical approach of service excellent" 
yang bertujuan untuk melatih memotivasi dan membangun komitmen yang tinggi dari para peserta mengenai konsep dan aplikasi service excellence pada Fakultas Hukum, Universitas Tarumanegara.

Adapun tujuan dari kegiatan penyuluhan ini adalah:

1. Menjelaskan tentang konsep service quality dan hubungannya dengan kepuasan dan loyalitas pelanggan serta tingkat keuntungan organisasi berdasarkan model service-value chain;

2. Menjelaskan bagaimana service quality diaplikasikan secara efektif pada perguruan tinggi;

3. Menjelaskan tentang enam tingkatan service quality;

4. Menjelaskan dan mengidentifikasi customer touch points.

Selain itu, kegiatan ini memberikan kemanfaatan bagi peserta pelatihan. Setelah mengikuti kegiatan penyuluhan ini, diharapkan dapat menambah pengetahuan dan meningkatkan motivasi, serta komitmen para dosen dan karyawan Fakultas Hukum, Universitas Tarumanegara dalam memberikan jasa pendidikan yang berkualitas tinggi kepada para mahasiswa dan stakeholder. Output ini bukan hanya akan meningkatkan produktivitas dan kualitas dosen dan karyawan tetapi juga akan meningkatkan produktivitas dan dampak positif bagi Universitas.

Untuk menjawab permasalahan tersebut di atas, diperlukan sebuah kegiatan penyuluhan tentang "practical approach of service excellence" kepada dosen dan karyawan Fakultas hukum, Universitas Tarumanegara. Banyaknya jumlah perguruan tinggi swasta yang menawarkan keunggulan program pendidikan masing-masing menjadi peluang sekaligus tantangan yang harus diantisipasi dengan baik oleh pihak internal institusi. Salah satu bentuk strategi yang dapat dilakukan dalam membangun citra positif dan loyalitas konsumen adalah dengan menawarkan pelayanan yang berkualitas. Diharapkan melalui penyuluhan ini, akan dihasilkan peningkatan pengetahuan, kesadaran, motivasi, serta komitmen para peserta dalam menjalankan tugas dan peran pada aktivitas belajar-mengajar dan pelayanan terhadap mahasiswa.

\section{METODE PELAKSANAAN}

Metode yang dilakukan dalam kegiatan penyuluhan ini adalah seperti berikut:

1. Para peserta diberikan pemaparan yang diisi dengan materi konsep dan ruang lingkup service quality, enam tingkatan service quality, dan customer touch points. Pada masing-masing bahasan akan diberikan contoh dan bentuk aplikasi efektif yang dapat dilakukan pada studi kasus perguruan tinggi.

2. Mengadakan sesi tanya jawab yang diharapkan menjawab masalah praktis yang dihadapi maupun konsep.

\section{HASIL DAN PEMBAHASAN}

Realisasi pemecahan masalah pada kegiatan pengabdian masyarakat ini dilakukan pada hari Sabtu, 1 Desember 2018 dengan mengadakan kegiatan berupa ceramah, tanya jawab dan diskusi mengenai hal-hal sebagai berikut:

1. Konsep dan ruang lingkup service quality berdasarkan model service-value chain;

2. Aplikasi service quality di perguruan tinggi;

3. Enam tingkatan service quality;

4. Customer touch points.

Ceramah disampaikan oleh Dr. Leonnard, SE, MComm membahas mengenai keempat poinpoin di atas. Pada paparan pertama dijelaskan mengenai definisi service quality dan aplikasi efektif yang dapat dilakukan. Konsep service quality didasarkan pada service-value chain yang menjelaskan mengenai prinsip-prinsip mendasar pemasaran pada sektor jasa, termasuk jasa pendidikan. Model ini secara khusus menguraikan hubungan sebab-akibat yang menunjukkan bagaimana kepuasan karyawan serta manajemen internal berkontribusi terhadap kualitas layanan dan kepuasan konsumen dan bagaimana mereka dapat mempengaruhi laba dan pertumbuhan organisasi (Heskett, Jones, Loveman, Sasser, \& Schlesinger, 1994). Hubungan antar bagian pada 
model ini ditunjukkan pada gambar 1.

Model service-value chain pada gambar 1 menjelaskan hubungan antara laba, kepuasan dan loyalitas konsumen, kepuasan dan loyalitas karyawan internal, dan produktivitas. Hubunganhubungan pada model tersebut dapat dijelaskan sebagai berikut:

Pertama, laba dan pertumbuhan organisasi dipengaruhi oleh loyalitas konsumen. Penelitian menunjukkan bahwa loyalitas konsumen memberikan pengaruh yang lebih besar bagi organisasi dibandingkan laba (Reichheld \& Sasser, 1990). Pada institusi penyedia jasa pendidikan seperti universitas, mahasiswa yang loyal bukan hanya memberikan manfaat bagi mereka sendiri untuk menyelesaikan pendidikan atau melanjutkan ke jenjang yang lebih tinggi, namun juga akan menjadi agen bagi calon mahasiswa untuk memilih institusi yang sama (Leonnard \& Susanti, 2018). Hal ini secara langsung akan memberikan dampak positif bagi pertumbuhan dan laba institusi, khususnya pada perguruan tinggi swasta yang tidak mendapatkan sumber dana langsung dari pemerintah.

Kedua, loyalitas merupakan hasil dari kepuasan konsumen. Konsumen yang puas merupakan hasil dari persepsi mereka terhadap service quality.
Jika persepsi tersebut melebihi ekspektasi, maka konsumen akan puas. Begitu pula sebaliknya (Gronroos, 1990). Ekspektasi konsumen terus mengalami perubahan, sehingga istilah melebihi ekspektasi harus dipandang sebagai sebuah usaha terus menerus organisasi dalam menyediakan jasa terbaik kepada konsumen mereka.

Ketiga, kepuasan konsumen dipengaruhi oleh nilai jasa yang diberikan. Kepuasan sering kali diungkapkan dalam bentuk emosi (Yu and Dean 2001; Oliver 2014) dan service excellent merupakan hasil dari perasaan yang dihasilkan dari spektrum emosi tersebut, dimana perasaan sangat puas merupakan hasil dari performa jasa yang luar biasa (Oliver, 2014).

Keempat, Nilai jasa yang diberikan kepada konsumen akan bergantung pada tingkat kepuasan, loyalitas dan produktivitas karyawan yang bekerja pada perusahaan / institusi penyedia jasa tersebut. Karyawan yang puas akan meningkatkan peluang untuk menghasilkan produktivitas yang tinggi bagi organisasi dan mengurangi keinginan mereka untuk keluar (Heskett, Jones, Loveman, Sasser, \& Schlesinger, 1994).

Kelima, kepuasan karyawan merupakan hasil dari segala bentuk kebijakan dan dukungan

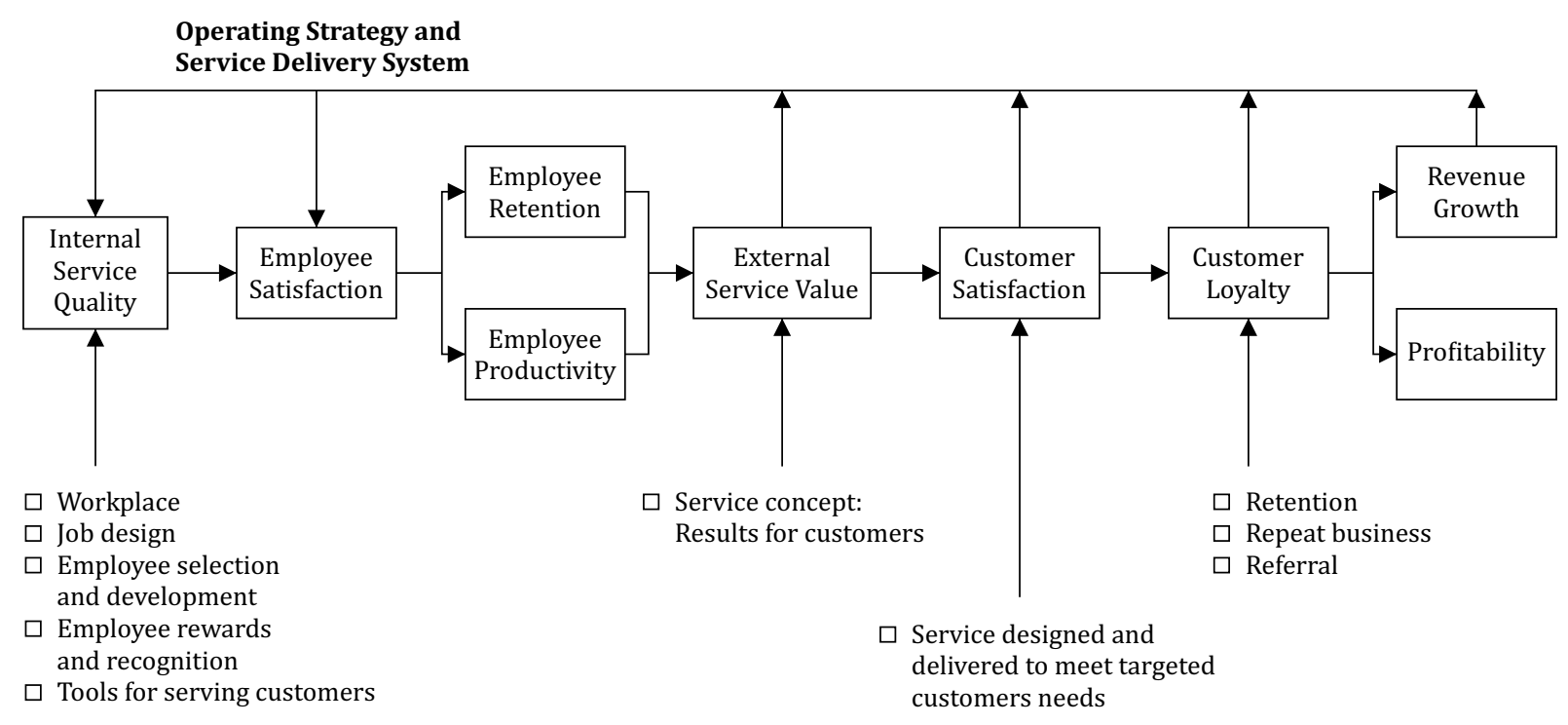

Sumber: Heskett, Jones, Loveman, Sasser, \& Schlesinger (1994)

Gambar 1. Hubungan pada model service-value chain 
perusahaan terhadap karyawan mereka dalam memberikan jasa kepada konsumen.

Kemudian pada paparan kedua dijelaskan secara spesifik mengenai aplikasi efektif service quality pada perguruan tinggi swasta, khususnya pada Fakultas Hukum, Universitas Tarumanegara. Bentuk pelayanan yang diberikan dapat berupa pelayanan internal (internal service quality) dan pelayanan eksternal (external service quality). Internal service quality merujuk kepada level kepuasan konsumen internal dari organisasi (Hallowell, 1996) yang dalam hal ini adalah dosen dan karyawan Fakultas Hukum, Universitas Tarumanegara.

Untuk menghasilkan level kepuasan ini, kepuasan individu-individu yang bekerja di internal organisasi harus dipenuhi terlebih dahulu. Individu-individu puas inilah yang mampu memberikan high service quality kepada konsumen eksternal (Khan, Safwan, \& Ahmad, 2011). Kualitas internal service quality ini dapat diukur melalui 3 aspek, yaitu: (1) kualitas tangible internal service quality yang meliputi pelatihan, insentif / gaji, dan program kesejahteraan karyawan, (2) intangible internal service quality yang meliputi komunikasi internal, (3) otonomi dan kebebasan karyawan ketika bekerja, dan kondisi lingkungan pekerjaan (Wang, 2011). Pada intinya internal service quality berkaitan dengan bagaimana karyawan diperlakukan oleh organisasi. Sedangkan external service quality berhubungan dengan segala bentuk jasa yang diberikan kepada mahasiswa dan stakeholder perguruan tinggi.

Terdapat berbagai macam pandangan dan pembuktian empiris mengenai atribut- atribut apa saja yang berkontribusi terhadap external service quality di perguruan tinggi. Di antara pendekatan yang paling popular untuk mengidentifikasi elemen-elemen service quality adalah SERVQUAL yang diusulkan oleh Parasuraman, Zeithaml, \& Berry (1988). Elemenelemen tersebut terdiri dari elemen tangibles, reliability, responsiveness, assurance, dan empathy. Beberapa di antaranya seperti diungkapkan oleh
Leblanc \& Nguyen (1997) yang terdiri dari reputasi, fasilitas fisik, administrasi, kurikulum, responsif, dan akses terhadap fasilitas.

Kemudian Lagrosen et al. (2004) menambahkan atribut-atribut lain seperti kerjasama institusi, kemampuan perguruan tinggi memberikan respons yang cepat dan tepat, arus informasi, mata kuliah yang ditawarkan, kegiatan belajarmengajar, ketersediaan fasilitas perpustakaan dan follow-up pasca kampus. Kedua bentuk service quality ini saling berhubungan dan keduanya harus diperhatikan dengan baik untuk mencapai kepuasan dan loyalitas konsumen seperti dijelaskan pada gambar 1 .

Sasaran dari kegiatan penyuluhan ini adalah para dosen dan karyawan Fakultas Hukum, Universitas Tarumanegara. Pada pelaksanaannya, kegiatan ini dihadiri oleh 22 orang dosen dan 19 orang karyawan.

\section{METODE PELAKSANAAN}

Kegiatan ini dilakukan dengan cara mengundang para dosen dan karyawan Fakultas Hukum, Universitas Tarumanegara, kemudian mendatangkan pembicara untuk memberikan materi yang diminta. Metode kegiatan yang digunakan pada kegiatan penyuluhan ini adalah metode ceramah, tanya jawab dan diskusi antara pembicara dengan peserta. Adapun waktu pelaksanaan kegiatan ini dilaksanakan pada hari Sabtu, tanggal 1 Desember 2018. Lokasi yang digunakan untuk kegiatan penyuluhan adalah di Ruang Volt, Museum Listrik, Taman Mini Indonesia Indah, Jakarta.

\section{KESIMPULAN DAN SARAN}

Kegiatan penyuluhan yang telah dilakukan, dapat disimpulkan bahwa peserta merasa senang dan puas dengan paparan materi yang diberikan. Para peserta mendapatkan pengetahuan dan keterampilan baru mengenai service quality secara praktis dalam konteks jasa pendidikan perguruan tinggi serta langkah-langkah efektif dalam pengaplikasiannya. Selain itu, penyuluhan ini juga memberikan motivasi bagi para peserta untuk berkomitmen dalam menjalankan langkah- 
langkah efektif yang diberikan melalui pemberdayaan dari internal customer Kegiatan penyampaian dilakukan dengan santai dan interaktif membuat para peserta dapat mengikuti kegiatan penyuluhan dengan sangat baik dari awal hingga akhir.

Berdasarkan evaluasi yang telah dilakukan dapat diajukan saran bahwa perlu dilakukan penyuluhan lanjutan yang lebih intensif, lebih dalam dan dilaksanakan secara periodik agar memberikan pengetahuan dan keterampilan lanjutan dan mengevaluasi praktik-praktik yang telah dilakukan sebagai tindak lanjut pelatihan /penyuluhan.

\section{DAFTAR PUSTAKA}

Grönroos, C. (1990). Service management and marketing: Managing the moments of truth in service competition. Jossey-Bass.

Hallowell, R., Schlesinger, L. A., \& Zornitsky, J. (1996). Internal service quality, customer and job satisfaction: Linkages and implications for management. Human resource planning, 19(2).

Heskett, J. L., Jones, T. O., Loveman, G. W., Sasser, W. E., \& Schlesinger, L. A. (1994). Putting the service-profit chain to work. Harvard business review, 72(2),164-174.

Khan, H., \& Matlay, H. (2009). Implementing service excellence in higher education. Education+ Training, 51(8/9), 769-780.

Khan, M.A., Safwan, N., \& Ahmad, A. (2011). Modeling link between internal service quality in human resources management and employee's retention: A case of Pakistani privatized and public sector banks. African Journal of Business Management, 5 (3), 949-959.

Lagrosen, S., Seyyed-Hashemi, R., \& Leitner, M. (2004). Examination of the dimensions of quality in higher education. Quality assurance in education, 12 (2), 61-69.

Leblanc, G., \& Nguyen, N. (1997). Searching for excellence in business education: an exploratory study of customer impressions of service quality. International Journal of Educational Management, 11 (2), 72-79.

Leonnard, L., Daryanto, H.K., Sukandar, D. and Yusuf, E.Z. (2015). The Loyalty Model of Private University Student. International Research Journal of Business Studies, 7 (1).

Leonnard and Susanti, Y. F. (2018). The advocacy model of Indonesian Chinese students, The affluent market. International journal of instruction, 12 (1).

Matlay, H. (2009). Entrepreneurship education in the UK: Acritical analysis of stakeholder involvement and expectations. Journal of small business and enterprise development, 16(2), 355-368.

Melnic, E. L. (2016). Techniques for measuring customers' satisfaction in Banks. Bulletin of the Transilvania University of Brasov. Economic Sciences. Series V, 9(1), 23.

Oliver, R. L. (2014). Satisfaction: A Behavioral Perspective on the Consumer: A Behavioral Perspective on the Consumer. Routledge.

Parasuraman, A., Zeithaml, V.A., \& Berry, L. L. (1988). Servqual: A multiple-item scale for measuring consumer perc. Journal of retailing, 64 (1), 12.

Reichheld, F. F., \& Sasser, J.W. (1990). Zero defections: Quality comes to services. Harvard business review, 68(5), 105-111. 
Spengler, C., \& Wirth, W. (2009). Maximising the impact of marketing and sales activities. IO new management, (3), 1-5.

Torres-Moraga, E., Vásquez-Parraga, A. Z., \& Zamora-González, J. (2008). Customer satisfaction and loyalty: start with the product, culminate with the brand. Journal of Consumer Marketing, 25 (5), 302-313.

Wang, G. L. (2011). A study of how the internal-service quality of international tourist hotels affects organizational performance: using employees' job satisfaction as the mediator. Journal of Global Business Management, $7(2), 1$.

Yu, Y. T., \& Dean, A. (2001). The contribution of emotional satisfaction to consumer loyalty. International journal of service industry management, 12 (3), 234-250. 